\title{
(t)
}

\section{AGRICULTURA DE SUSTENTAÇÃO SOB OLHARES DE JOSUÉ DE CASTRO}

\author{
Sustainable agriculture under the eyes of Josué de Castro
}

\section{Sirlândia Schappo ${ }^{1}$}

\section{RESUMO}

A questão agrária, enquanto um elemento fundamental para análise da realidade nacional, assim como para a formação e atuação do Assistente Social, remete-nos a pensar como essa questão se configura na particularidade da formação sócio-histórica brasileira. Este artigo apresenta as principais análises de Josué de Castro sobre a agricultura de sustentação, bem como a relevância delas para se pensar projetos de vida e de trabalho no campo que se estabelecem em direção oposta aos princípios que regem os grandes empreendimentos agropecuários capitalistas. O termo agricultura de sustentação é utilizado por Josué para definir os cultivos que possibilitam a ampliação das possibilidades alimentares de uma região. Uma agricultura em que se encontram presentes relações de cooperação, policultivos, práticas sustentáveis em termos econômicos, sociais, ambientais e culturais. Josué destaca os históricos cultivos tradicionais, especialmente dos quilombolas e sertanejos, revelando a importância da agricultura de sustentação no combate à fome.

\section{PALAVRAS-CHAVE}

Josué de Castro. Agricultura de sustentação. Questão agrária.

\footnotetext{
${ }^{1}$ Doutora em Sociologia pela Unicamp (2008) e Professora do Departamento de Serviço Social da Universidade Federal de Santa Catarina. E-mail: <sschappo@ gmail.com>.
} 


\section{ABSTRACT}

The agrarian question, as a key element for analysis of national reality, as well as in formation and Social Worker actuation, leads us to think about how this question is configured in the brazilian socio-historical formation. This article presents the main analysis of Josué de Castro on sustainable agriculture, as well as the relevance of these analysis to think about life projects and working in rural world that are established into opposite direction to the principles governing the great capitalist agricultural enterprises. The term sustainable agriculture is used by Josué to define the cultivations that provide the increase of the feeding possibilities in a region. An agriculture where we find relations of cooperation, polyculture, practices economically, socially, environmentally and culturally sustainable. Josué highlights the traditional cultivations, especially of quilombolas and sertanejos, revealing the importance of sustainable agriculture on the battle against hunger.

\section{KEYWORDS}

Josué de Castro. Sustainable agriculture. Agrarian question.

Submetido: 25/5/2012

Aceito: 1/8/2012

\section{INTRODUÇÃO}

Refletir sobre a questão agrária, enquanto um elemento fundamental para análise da realidade nacional, assim como para a formação e atuação do Assistente Social, remete-nos a pensar como essa questão se configura na particularidade da formação sócio-histórica brasileira. Esta particularidade incide sobre consensos, controvérsias, correlações de forças, hegemonia, contra-hegemonia, avanços e retrocessos da sociedade civil, assim como nas expressões da questão social. Nesse intuito, contamos com a contribuição de autores clássicos e contemporâneos do pensamento social crítico brasileiro e suas interpretações sobre o país. Como afirma Elide Rugai Bastos, o estudo sobre os intelectuais e sua interpretação do país é componente fundamental da busca de explicações sobre o Brasil (BASTOS, 2002). Nesse texto, discutem-se as contribuições de Josué de Castro (1908-1973) sobre a agricultura de sustentação, destacando-se sua importância para se pensar a questão agrária na formação sócio-histórica do Brasil, assim como na atualidade. 
As diretrizes curriculares para o curso de Serviço Social destacam, entre os núcleos constitutivos da formação profissional, o de Fundamentos da Formação Sócio-histórica da Sociedade Brasileira. Este núcleo abrange a compreensão da sociedade brasileira, suas características históricas particulares que presidem a sua formação e o seu desenvolvimento, e suas diversidades regionais e locais. Compreende, ainda, a análise do significado do Serviço Social em seu caráter contraditório, no bojo das relações entre as classes e destas com o Estado, abrangendo as dinâmicas institucionais nas esferas estatal e privada (BRASIL, 2009). Nesse sentido, enfatiza-se a relevância de uma análise das particularidades da formação sócio-histórica do Brasil, destacando-se as principais ideias de Josué de Castro sobre a agricultura de sustentação que contribuíram para a superação das concepções naturalizadoras da questão social.

Marilda Villela lamamoto, ao analisar os inúmeros desafios profissionais e acadêmicos que se apresentam ao Serviço Social na atualidade, ressalta a importância de uma apreensão do legado do pensamento social crítico brasileiro, entre eles o de Josué de Castro:

O legado já acumulado pelo pensamento social crítico brasileiro sobre a interpretação do Brasil no quadro latino-americano também necessita ser re-apropriado para, a partir dele, elucidar as particularidades dos processos sociais que conformam o Brasil no presente, solidificando as bases históricas do projeto profissional. E aprender com os nossos clássicos. Refiro-me a autores como: Caio Prado Junior, Nelson Werneck Sodré, Florestan Fernandes, Antônio Cândido, Josué de Castro, Celso Furtado, Hélio Jaguaribe, Octavio lanni, Ruy Mauro Marini, entre outros. As transformações históricas que tiveram lugar tanto no Brasil e nos demais países latino-americanos foram por eles assumidas como desafios ao pensamento (IAMAMOTO, 2009, p. 39).

Josué de Castro destaca-se, como afirma Marilda lamamoto, entre os autores que pensaram o Brasil de forma crítica, demonstrando os processos sociais que conformam o país no presente, contribuindo para solidificar as bases históricas do projeto profissional. A importância da leitura dos clássicos do pensamento social crítico 
brasileiro e de suas proposições revela-se, ainda, pela consagração deles enquanto autores autênticos de seu tempo, desvendando desigualdades gestadas a partir de um processo de modernização perversa. Josué de Castro se aproximava do grupo de autores considerados críticos, estes pensavam e revelavam questões de um Brasil, até então, obscuras, com vistas à construção de um novo projeto de sociedade.

No ano de 2008, comemorou-se, em diferentes regiões do Brasil e do mundo, o centenário de nascimento de um intelectual que se dedicou incessantemente na luta contra a fome: o pernambucano Josué Apolônio de Castro (1908-1973). No mesmo ano, a atualidade de suas ideias destacou-se pelo fato de que diversos países presenciaram fortes aumentos dos preços dos alimentos, manifestações e conflitos frente à crise alimentar global. O centenário de nascimento de Josué de Castro foi marcado por cerca de um bilhão de pessoas famintas no mundo e, ao mesmo tempo, pela expansão da inovação agropecuária e do agronegócio. Nesse contexto, coexistem, ainda, a depredação da fauna, da flora e do meio ambiente, a generalização da violência, a escravidão por dívida, as desigualdades, entre outros fatores que nos distanciam dos ideais de Josué de Castro, mas que, por outro lado, revelam a sua importância e atualidade.

No pensamento e na trajetória intelectual de Josué de Castro, destaca-se uma constante e concisa análise da fome como uma expressão da questão agrária e a importância da agricultura de sustentação no combate à fome. O termo agricultura de sustentação é utilizado por Josué para definir os cultivos que possibilitam a ampliação das possibilidades alimentares de uma região. Uma agricultura em que se encontram presentes relações de cooperação, policultivos, práticas sustentáveis em termos econômicos, sociais, ambientais e culturais importantes para a constituição de uma alimentação variada e rica em nutrientes. Josué destaca os históricos cultivos tradicionais, especialmente dos negros quilombolas e sertanejos, revelando a importância da agricultura de sustentação no combate à fome.

A agricultura de sustentação situa-se na obra do autor em diferentes espaços e temporalidades. Destaca-se a análise que o autor realiza sobre a agricultura nos quilombos e no Sertão do Nordeste em 
oposição ao Norte Açucareiro. Espaços geográficos que refletem predominantemente dois modos de produção e de vida distintos: policultura $x$ monocultura, trabalho familiar $x$ trabalho assalariado, pequena propriedade $x$ grande propriedade, agricultura de subsistência $x$ agricultura mercantil, preservação x degradação ambiental, fome epidêmica $x$ fome endêmica.

\section{A AGRICULTURA DE SUSTENTAÇÃO NA OBRA DE JOSUÉ DE CASTRO}

A comunidade camponesa pode ser considerada por muitos como ilusória, pretérita, romântica, porém, como destaca lanni (2009, p. 138), “[...] pode ser uma metáfora do outro mundo". Nesse sentido, destaca-se que a importância da agricultura de sustentação ensejada na obra de Josué de Castro representa a construção de um modo de vida e de trabalho que se estabelece em direção oposta aos grandes empreendimentos capitalistas no meio rural. A atualidade da agricultura de sustentação encontra-se expressa na luta dos trabalhadores do campo por um projeto sustentável de vida e de trabalho frente à expansão do agronegócio. O caráter radical deste projeto e das lutas dos trabalhadores camponeses encontra-se justamente nos obstáculos que ele representa à expansão do Capitalismo no campo:

De fato, o movimento social camponês não se propõe à conquista do poder estatal, à organização da sociedade nacional, à hegemonia camponesa. Essas talvez sejam tarefas do partido político. Pode ser a tarefa da classe operária, associada com outras categorias sociais, inclusive o campesinato. Mas isso não elimina nem reduz o significado revolucionário das muitas lutas que esse movimento realiza. Em essência, o seu caráter radical está no obstáculo que representa à expansão do capitalismo no campo; na afirmação da primazia do valor de uso sobre o valor de troca, sobre a produção de valor, sobre o trabalho alienado; na resistência à transformação da terra em monopólio do capital; na afirmação de um modo de vida e trabaIho de cunho comunitário (IANNI, 2009, p. 138-139).

Ianni (2009) contribui, assim, para destacar a importância do campesinato nas resistências frente à expansão do capital, revelando a especificidade do modo de vida e de trabalho camponês. Enquanto 
que, para o capitalista a mão-de-obra assalariada, o trabalho precário e a apropriação da mais-valia no processo de produção são importantes fontes de renda, na produção camponesa, se produz e se consome familiarmente. Nesse sentido, conforme as análises clássicas de Chayanov (1974), o resultado do trabalho dos membros da família é calculado segundo o atendimento ou não das necessidades do grupo familiar. Flexibilidade, caráter familiar da mão-de-obra e a não objetivação do lucro são características que marcam esse processo.

A relação com a natureza é outro elemento que revela especificidades da agricultura camponesa. Enquanto esta é fortemente baseada no capital ecológico, especialmente na natureza viva, a agricultura empresarial afasta-se progressivamente da natureza. Insumos e outros fatores artificiais de crescimento substituem os recursos naturais, o que significa que, nesse último modelo, a agricultura está sendo industrializada. Além disso, destaca-se a indispensável contribuição da agricultura camponesa para a produção de alimentos, a geração de emprego e renda, a sustentabilidade e o desenvolvimento de modo geral (PLOEG, 2009).

No Brasil, a grande propriedade sempre se impôs como modelo socialmente reconhecido, especialmente nas políticas agrícolas. Neste contexto, a agricultura familiar sempre ocupou lugar secundário e subalterno. Foi, historicamente, um setor bloqueado em suas potencialidades (WANDERLEY, 1996). A autora destaca que a história do campesinato no Brasil pode ser definida como o registro das lutas para conseguir um espaço próprio na economia e na sociedade, destacando alguns elementos fundamentais da história do campesinato brasileiro: as lutas por um espaço produtivo, pela constituição do patrimônio familiar e pela estruturação do estabelecimento como um espaço de trabalho da família.

É a partir do contexto brasileiro de luta pela terra e por um espaço de vida e de trabalho que Josué de Castro desenvolve suas análises que revelam a importância da agricultura de sustentação, em especial, aquela praticada por negros quilombolas e sertanejos. No ano de 1945, antes de publicar seu clássico livro Geografia da fome (1946), Josué antecipa parte essencial desse livro em um artigo publicado na Revista América Indígena. Nele, o autor destaca que os 
recursos alimentares defeituosos no Brasil decorrem de uma estrutura econômico-social que sempre trabalhou num sentido desfavorável ao aproveitamento racional de nossas possibilidades geográficas. Apesar dos primeiros colonizadores trazerem a tradição da policultura e de um bom regime alimentar, estas tradições não foram mantidas em decorrência do desenvolvimento da monocultura mercantil sob o alicerce do latifúndio.

Os colonizadores portugueses preocupados pela am-
bição de enriquecer depressa, de fazerem-se donos
da terra, do seu ouro e de seus tesouros, em lugar de
continuarem na colônia a rotina do cultivo de plantas
de sustentação que Ihe forneceriam recursos de uma
alimentação completa, lançaram-se com furor, ou na
monocultura do açúcar, ouro branco, que exportado,
Ihe proporcionava lucros fabulosos, ou na busca dire-
ta do ouro, oculto nos filões da terra. E nestes miste-
res mercantis abandonaram por completo sua tradi-
ção de poliagricultura e rebaixaram, deste modo, o
seu padrão alimentar (CASTRO, 1945, p. 192).

Observa-se, em seu pensamento, a importância da agricultura de sustentação no combate à fome e os limites impostos para o seu desenvolvimento decorrentes de um processo de colonização baseado na monocultura e no latifúndio. Em Geografia da fome, Josué destaca que a policultura foi praticamente abandonada pelo furor da monocultura. Nessa obra, o autor identifica cinco diferentes áreas alimentares, destas, três são por ele consideradas nitidamente áreas de fome e é nelas que o autor prioriza sua análise: a Área Amazônica, Área do Norte Açucareiro e a do Sertão Nordestino (CASTRO, 1946).

Na análise que o autor desenvolve sobre a importância da agricultura de sustentação no combate à fome, destacam-se: a valorização do sertanejo e suas formas de cultivo, a diferença da produção e da alimentação entre as áreas Zona da Mata e Zona do Sertão, a desmistificação do Nordeste enquanto uma região naturalmente problemática, a crítica ao modelo de industrialização adotado no país, a oposição aos preconceitos de raça e de clima, os quilombos e a policultura praticada pelos negros, a migração rural-urbana, a fome, a seca, e as condições de vida dos trabalhadores no meio rural e no meio urbano, entre outras. 
Nas proposições de Josué de Castro, o combate ao latifúndio e à monocultura aparece como essencial para se pensar um plano de alimentação para o país. Suas ideias encontravam-se inseridas nas discussões daquela época que visavam a uma solução para a problemática da alimentação, agravada com o processo de urbanização. O período é marcado por um clima de preocupação política frente à amplitude e ao aprofundamento da crise alimentar que o país enfrentava.

Castro (1946) ressalta a importância de se incrementar a produção por meio da ampliação das possibilidades para o desenvolvimento da agricultura intensiva de subsistência². Para agir sobre a alarmante situação em que o país vivia em termos de alimentação, Josué alerta para que as elites dirigentes, o governo, as classes intelectuais e produtivas encarem o problema em suas devidas proporções e propõe que se formule um plano sistematizado de política alimentar. Para este plano, Josué destaca como urgente o incremento da produção com o combate aos latifúndios e à monocultura e sugere o incentivo à policultura por meio de uma modernização intensiva, diferentemente, portanto, daquela que predominava nas grandes propriedades monocultoras. Propõe, ainda, o incentivo ao cooperativismo e ao cultivo dos produtos de sustentação por meio da isenção de impostos. Medidas estas visualizadas pelo autor como uma saída para a crise alimentar do país.

No artigo publicado em 1945, Josué destaca a relevância dos cultivos dos negros na alimentação brasileira. Trazendo da África uma boa tradição agrícola, o negro foi a "[...] força criadora de nossa agricultura e contribuiu para que os nossos recursos alimentares não se tornassem ainda mais exíguos" (CASTRO, 1945, p. 192). Josué deixa transparecer o que concebe como "[...] boa tradição agrícola [...]" ou, simplesmente, “[...] agricultura [...]". O autor valoriza, na formação sócio-histórica do país, a agricultura de sustentação, ou seja, a que contribuiu para uma ampliação de nossas possibilidades alimentares. A preocupação de Josué vai além da tentativa de desmistificar preconceitos raciais, pois abrange, no caso do negro, um modo de vida e de cultivo: a agricultura de sustentação. Esta

\footnotetext{
${ }^{2}$ Quando o autor se referia à agricultura intensiva de subsistência, opunha-a à agricultura extensiva, ao monocultivo de alguns produtos para exportação.
} 
foi limitada por uma estrutura econômica e social historicamente marcada pela opressão do latifúndio e da monocultura.

\begin{abstract}
Como povo de tradição agrícola, de tipo de agricultura de sustentação, o negro reagia contra a monocultura, de forma mais produtiva do que o índio. Desobedecendo as ordens do senhor e plantando às escondidas seu roçadinho de mandioca, de batata-doce, de feijão e de milho. Sujando aqui, acolá, o verde monótono dos canaviais com manchas diferentes de outras culturas. Benditas manchas salvadoras da monotonia alimentar da região. Que o negro nunca perdeu esse instinto policultor, esse amor à terra e às plantações, apesar da brutalidade com que fora arrastado de sua terra, com todas suas raízes culturais violentamente arrancadas (CASTRO, 1946, p. 114).
\end{abstract}

Estes roçados baseados na policultura, tão benéficos para as condições alimentares da região, foram, em diversas ocasiões, violentamente destruídos por um sistema econômico e opressor que não impunha limites às ações. Para a análise desta questão, Josué utiliza como fonte teórica o livro República dos Palmares, de Edison Carneiro, publicado em 1946. Carneiro (1958) afirma ser o movimento de fuga para os quilombos uma negação da sociedade oficial, que oprimia os negros escravos, eliminando a sua língua, a sua religião e os seus estilos de vida. O quilombo representava uma reafirmação da cultura e dos estilos de vida africanos. Na concepção de Carneiro, a regra no quilombo era a pequena propriedade e a policultura em torno de vários mocambos, um sistema no qual predominava a "posse útil da terra".

Do ponto de vista aqui considerado, se, por um lado, os negros tiveram de adaptar-se às novas condições ambientes, por outro lado o quilombo constituiu, certamente, uma lição de aproveitamento da terra, tanto pela pequena propriedade como pela policultura, ambas desconhecidas da sociedade oficial. (CARNEIRO, 1958, p. 25). ${ }^{3}$

Edson Carneiro exerce uma influência marcante no pensamento de Josué ao demonstrar a importância do movimento negro na

\footnotetext{
${ }^{3}$ A edição consultada é a segunda, na qual o título passa a ser $\mathrm{O}$ quilombo dos Palmares, porém, nela, constam todas as citações utilizadas por Josué de Castro, referentes à primeira edição.
} 
luta contra a monocultura e no desenvolvimento de um regime de policultura, uma das principais atividades dos negros nos quilombos. ${ }^{4}$ Cultivavam milho, batata-doce, feijão, mandioca, bananas (pacovas) e outras plantas alimentares (CASTRO, 1946, p. 135). Nessa agricultura, ajustavam-se os recursos naturais às necessidades do homem. Roçados que sujavam o verde monótono dos canaviais, salvando a monotonia alimentar na região.

Porém, inúmeras foram as expedições baseadas estrategicamente na destruição prévia dos roçados de subsistência. Foi assim que, segundo Josué, a ação restauradora do negro foi limitada, não adquirindo uma consistência e extensão capazes de atuar decisivamente na economia do país. Na análise de Josué, os negros contribuíram para a ampliação da policultura, amenizando os efeitos maléficos da monocultura na alimentação. As possibilidades alimentares geradas a partir dos quilombos contrastam com as condições de vida nas demais áreas do Norte Açucareiro. Josué analisa que, em regiões onde se destaca o sistema monocultor e latifundiário, os regimes alimentares e as condições de vida em geral da população são precários.

Josué argumenta que, no Norte Açucareiro, a fome é permanente, endêmica, enquanto no Sertão nordestino, ela decorre de fatores climáticos, sendo epidêmica. Seus estudos e comparações regionais, em Geografia da fome, destacam que, em períodos não assolados pela seca, o Sertão oferece melhores condições de alimentação que a região da monocultura da cana-de-açúcar. Nesta, predominou uma economia cujo fim não era o homem e suas necessidades, mas a busca do lucro em ciclos sucessivos de economia destrutiva. Este argumento contribui para desnaturalizar as causas da fome, revelando que ela é antes uma expressão da questão agrária do que simplesmente uma consequência das secas. Esta compreensão emerge de uma análise minuciosa desenvolvida pelo autor sobre a agricultura de sustentação pra-

\footnotetext{
$\overline{{ }^{4} \text { Cardoso (2009) }}$ analisa que os escravos também cultivavam produtos para alimentação, aos quais eram atribuídas parcelas de terras e tempo para cultivá-las. Porém, o tempo a elas disponibilizado era restrito, especialmente aos domingos e feriados, sendo assim, secundárias em relação ao escravismo dominante, além disso, exerciam uma funcionalidade no sentido de reproduzir o próprio sistema escravista.
} 
ticada pelo sertanejo em períodos de clima normal. Seus estudos baseiam-se nas pesquisas etnográficas de Luís da Câmara Cascudo e nos escritos sociais nordestinos (SCHAPPO, 2008).

Segundo Josué, o sertanejo não se dedicou a uma atividade exclusiva que seria extremamente nociva à sua vida econômica, ele tornou-se vaqueiro e agricultor ao mesmo tempo.

\begin{abstract}
Não se constituiu o sertanejo num agricultor de produtos de exportação, para fins comerciais, como se praticava nas terras do litoral, mas um plantador de produtos de sustentação para seu próprio consumo. Um semeador, em pequena escala, de milho, feijão, fava, mandioca, batata-doce, abóbora e maxixe, plantados nos vales mais sumosos, nos baixios, nos terrenos de vasante, como culturas de hortas e jardins. Pequenas boladas de verdura que os senhores de engenho do brejo, plantadores de extensíssimos canaviais sempre olharam com desdém, chamando depreciativamente a êste tipo de policultura do sertanejo, de 'roça de matuto'. Roças de matuto diante das quais o homem do açúcar torcia o nariz de grande senhor agrário, e que, no entanto, vieram a constituir um magnífico elemento de valorização das condições de vida regional, de diversificação do regime alimentar do sertanejo, bem superior em épocas normais ao da área da cana (CASTRO, 1946, p. 198-199).
\end{abstract}

Josué de Castro destaca, assim, o papel dos cultivos característicos da policultura na ampliação das possibilidades alimentares de diferentes regiões e em distintos contextos. Geralmente, eles aparecem em oposição à monocultura e ao latifúndio impostos pelos colonizadores na busca incessante e desvairada de riquezas que destrói os recursos alimentares e naturais. Duas formas de agricultura que se contrapõem em termos de sustentabilidade ambiental e social. É a partir desse intuito que ele propõe, na década de 1950, um projeto de reforma agrária, visando à ampliação das possibilidades alimentares por meio dos suportes necessários ao desenvolvimento da agricultura de sustentação. O pensamento de Josué de Castro, na primeira edição de Geografia da fome (CASTRO, 1946), não esboça ainda um nítido projeto de reforma agrária objetivando uma ampla distribuição de terras, como em edições posteriores do livro. No entanto, são incisivas suas afir- 
mativas sobre a necessidade de um plano de política alimentar que tem, entre suas metas, o combate ao latifúndio improdutivo e à monocultura, e o incentivo à agricultura de sustentação.

\section{AGRICULTURA DE SUSTENTAÇÃO: BLOQUEIOS, CONFLITOS E ATUALIDADES}

Além das dificuldades de acesso a terra no Brasil, historicamente, a agricultura de sustentação foi limitada pela tentativa de transformar os cultivos tradicionais pela chamada verdadeira agricultura. Esse contexto das primeiras décadas do século XX é evidenciado nos escritos de Carvalho (1941). Daniel de Carvalho 5 apresenta propostas e ideias pertinentes à estratégia conservadora de modernização no campo, incutida tanto nos discursos quanto nas práticas políticas que visavam a tomar medidas corretivas para sanar determinados problemas no setor agrícola e evitar, assim, uma mudança na estrutura agrária ${ }^{6}$; mudar, inovar no plano técnico, instrumental e científico sem que as bases da estrutura agrária fossem abaladas. Desde a década de 1920, observam-se ideais de uma modernização conservadora no imaginário de Daniel de Carvalho, reproduzidos em diversos de seus discursos como paraninfo em cursos de Agronomia, como o intitulado Volta aos campos (para a turma de agrônomos da Escola D. Bosco, em Cachoeira do Campo - MG) no dia 20 de novembro de 1924:

Como o problema brasileiro é essencialmente um problema de produção agrícola, conforme o demonstrou João Pinheiro, em páginas imortais, é mister gravar no espírito, divulgar e repetir o conceito luminoso de Raul Soares: Cumpre ao governo ter suas vistas permanentemente voltadas para o trato nobilitante da terra, encaminhar um pouco de civilização e de conforto para a vida das fazendas, persistir na nossa regeneração agrária, atenuar, suprimir todos os embaraços ao desenvolvimento agrícola (CARVALHO, 1941, p. 48-49).

\footnotetext{
${ }^{5}$ Ministro da Agricultura no Governo de Eurico Gaspar Dutra e um dos principais idealizadores do projeto de reforma agrária daquele Governo.

${ }^{6} \mathrm{Em}$ 1947, é lançado, por iniciativa do governo, em especial do Ministério da Agricultura e de seu Ministro Daniel de Carvalho, o projeto de Reforma Agrária. Este projeto apresenta-se de forma a amenizar a radicalidade em torno distribuição de terras propostas três meses antes no projeto pioneiro de Nestor Duarte, o qual abre a discussão sobre o tema no Congresso.
} 
Os discursos de Daniel de Carvalho expressavam a necessidade de transformar os processos empíricos de exploração da terra herdados dos índios e dos negros em uma verdadeira agricultura. A proposta referia-se à modernização, comercialização e industrialização da agricultura, com a permanência das garantias jurídicas do direito à propriedade. As medidas a serem tomadas não expressam a necessidade de uma reforma agrária e sim abrange os problemas ligados à produção e à comercialização agrícola: fundação de escolas de Agronomia, criação de crédito agrícola, abertura de estradas, saneamento rural, entre outras.

Na segunda metade do século XX, a Revolução Verde, a partir de uma perspectiva produtivista, desencadeou um processo contraditório de explosão da produtividade, mas também da desigualdade entre os diferentes países, da fome e da pobreza. Esse processo intensificou a concorrência da agricultura dos países desenvolvidos, resultando na chegada de cereais a baixo preço nos países em desenvolvimento, ocasionando nestes uma redução da produção de alimentos e ampliação da dependência alimentar (MAZOYER; ROUDART, 1998). Esse cenário apresenta explosões periódicas e passageiras dos preços, baixos salários, concentração de capitais e de terras (muitas destas, anteriormente, produziam alimentos), mudança de foco da produção de alimentos para produtos de exportação, entre outras questões que impõem limites para o desenvolvimento da agricultura de sustentação.

Neste sentido, diversos autores, análises e pesquisas apontam para uma questão presente de forma significativa nos argumentos de Josué de Castro: a falta de alimentos para grande parte da população é fruto de um processo histórico de desenvolvimento desigual e não pode ser resolvida com o simples aumento da produção. A crise agrária e alimentar é, atualmente, agravada pela perspectiva produtivista presente na concentração de investimentos no modelo industrial de produção e comercialização agrícola, pela interação de três processos interdependentes:

A atual crise agrária emerge a partir da interação entre (1) a parcial, ainda que progressiva, industrialização da agricultura, (2) a introdução do mercado global como princípio ordenador da produção e co- 
mercialização agrícola e (3) a reestruturação da indústria de processamento, de grandes empresas de comercialização e de cadeias de supermercados em impérios alimentares que exercem um poder monopólico crescente sobre as relações que encadeiam a produção, o processamento, a distribuição e o consumo de alimentos. A fusão desses três processos, criando um novo e global regime alimentar, está afetando profundamente a natureza da produção agrícola, os ecossistemas nos quais a agricultura está enraizada, a qualidade do alimento e as suas formas de distribuição (PLOEG, 2009, p. 23).

O autor analisa que a crise atual é decorrente desse processo que tem como base os modos empresariais e capitalistas de produção agrícola, implicando uma desconexão da agricultura com a natureza e com as localidades. Fatores naturais (tais como fertilidade do solo, variedades cuidadosamente selecionadas, entre outros) têm sido progressivamente substituídos por fatores artificiais que se expressam na forma de insumos externos e novos equipamentos tecnológicos. Em vez de ser construída em função do capital ecológico, a produção agrícola se torna, nesse processo, dependente do capital industrial e financeiro.

Os estudos realizados pela ONG ActionAid, em 2009 e 2010, revelam, nos relatórios Who's Really Fighting Hunger? (2009; 2010), o desempenho de vários países para combater a fome. Os estudos destacam, entre os fatores que agravam a crise alimentar: a liberalização do comércio que tem aprofundado a dependência da importação de alimentos e a vulnerabilidade à variação do preço global, e as políticas de incentivo ao uso de biocombustíveis que está contribuindo para a volatilidade dos preços dos alimentos, prejudicando, ainda mais, os pequenos agricultores.

Entre as ações necessárias para combater a fome, os relatórios destacam: a liderança forte do Estado para investir em pequenos agricultores que cultivam a maioria dos alimentos, ampliar a proteção social, instituir a alimentação adequada como um direito legal, combater as alterações climáticas, incentivar a agricultura familiar sustentável e eliminar subsídios para produção de biocombustível, que solapam diretamente a segurança alimentar. 
Os relatórios expressam que a fome entre os produtores de alimentos no mundo em desenvolvimento é uma realidade irônica. Sete em cada dez pessoas com fome no mundo são agricultores sem terra ou pequenos agricultores ou trabalhadores agrícolas. Os países em desenvolvimento foram forçados a abolir os apoios para os pequenos agricultores e a abrir seus mercados para importações baratas ao longo das últimas décadas. Isso tem deixado o mundo em uma situação em que os países pobres convivem com a insuficiência alimentar de suas populações e de seus agricultores que encontram dificuldades para alimentar até as próprias famílias.

Quanto ao Brasil, os relatórios destacam as políticas sociais adotadas pelo governo federal para reduzir a fome no país, os efeitos positivos de programas como o Bolsa Família e o Fome Zero. No entanto, os relatórios enfatizam a concentração de investimentos em agronegócio. "No Brasil, a capacidade de subsistência de muitas comunidades cercadas pelo eucalipto, soja ou cana-de-açúcar tem sofrido muito com a crescente expansão do agronegócio" (ACTION AID, 2009, p. 20). Os incentivos governamentais apontam para uma promoção, especialmente dos biocombustíveis, em detrimento da produção de alimentos, o que deveria ser evitado, pois, com a expansão dos biocombustíveis, elevam-se os preços da terra e convertem-se cultivos de alimentos em produção de biocombustíveis (ACTION AID, 2010, p. 37).

Este cenário retrata o que Heredia; Palmeira e Leite (2010, p. 165) constatam a partir de uma pesquisa de campo sobre as sociedades do agronegócio no Brasil: “[...] são os enormes investimentos que põem em evidência o fato de que não se pode falar do agronegócio sem pensar no Estado e nas políticas públicas, que não só viabilizam sua origem mas sua expansão".

A expansão do Capitalismo no mundo agrário contribui para a restrição das bases essenciais para o desenvolvimento da agricultura de sustentação, expandindo-se a partir das mais diversas violências marcadas pela acumulação e monopolização da propriedade, e da exploração da terra, do homem e da natureza. No entanto, se por um lado, a luta pela terra, a violência política e costumeira dos proprietários fundiários e a seletividade do Estado nos conflitos 
agrários indicam a continuidade do processo de dilaceramento da cidadania no campo, por outro, revelam também o vigor das lutas agrárias (SANTOS, 2000).

Entre os diferentes tipos de violência que configuram esse processo: costumeira, política, simbólica, programada, Santos (2000) apresenta também uma face da violência que, geralmente, não aparece com este caráter, que é a violência derivada do tipo de relação do homem com a natureza, ou seja, a violência ecológica, ação que depreda a fauna, a flora e o meio ambiente. $O$ autor questiona alguns paradoxos da sociedade brasileira contemporânea, como, por exemplo, o aumento da modernização e generalização da violência, expansão da inovação agropecuária e dos complexos agroindustriais e a coexistência de trabalho escravo. Cabe destacar outros paradoxos também presentes a partir do desenvolvimento do Capitalismo no campo: expansão da produtividade e aumento da fome, crescimento de riquezas e ampliação das desigualdades, inovações tecnológicas e destruição ambiental, entre outros.

A partir desses paradoxos, ainda presentes na atualidade, afirma-se a relevância e atualidade das ideias e do projeto político ensejado por Josué de Castro. Um projeto que se revigora em diferentes lutas e conflitos agrários frente à expansão do Capitalismo no campo. Resistências e lutas que são atuais expressões da agricultura de sustentação e de sua relevância no fortalecimento de formas de vida e de trabalho sustentáveis no campo e na ampliação das possibilidades alimentares no país. Essas expressões podem ser identificadas por meio de diferentes pesquisas e análises teóricas, Petersen (2009); Altieri (2010); Santos Ferrante (2003), (PETERSEN; DAL SOGLIO; CAPORAL, 2009), entre outros que reforçam esta questão na atualidade, em diferentes iniciativas, perspectivas, formas de cultivos e modos de vida: agricultura familiar camponesa, populações tradicionais, revalorização dos conhecimentos tradicionais de pequenos agricultores, a consolidação da Agroecologia e as críticas à agricultura convencional e ao viés produtivista da Revolução Verde, entre outras.

\section{CONSIDERAÇÕES FINAIS}

A agricultura de sustentação analisada por Josué de Castro expressa, transcendendo temporalidades, resistências, lutas e projetos 
de vida e de trabalho que se colocam como obstáculos à expansão do Capitalismo no campo. Nela, prioriza-se o uso da terra, da natureza e do trabalho para o atendimento das necessidades humanas básicas, entre elas, uma das mais elementares: a alimentação. Esta prioridade encontra-se presente nos diferentes exemplos destacados por Josué de Castro na agricultura praticada por quilombolas e sertanejos, porém, encontra-se ausente em muitos dos "modelos" agrários de nossa insistente modernização conservadora.

Pode-se aferir que, nas últimas décadas do século XX, consolidam-se as consequências e as críticas à perspectiva produtivista na agricultura e a possibilidade de construção de alternativas, mais justas do ponto de vista social, cultural e ambiental. A agricultura de sustentação concebida por Josué de Castro expressa sua relevância e atualidade, demonstrando um papel importante em uma estratégia de (des)envolvimento que engloba a Soberania e a Segurança Alimentar e Nutricional. Ela estimula a produção diversificada, amplia a capacidade de consumo de alimentos e contribui para a meIhoria das condições de vida das famílias que a praticam. O projeto de agricultura de sustentação ensejado por Josué abrange, assim, as atividades agrícolas, o território e a luta pelo usufruto da terra em benefício do bem-estar social, cumprindo papel decisivo para incentivar as potencialidades da Agroecologia, e das sociedades camponesas e seu patrimônio sócio-cultural.

\section{REFERÊNCIAS}

BRASIL. Diretrizes Curriculares Curso de Serviço Social. Brasília, 26 fev. 1999. Disponível em: <http://www.abepss.org.br/briefing/graduacao/ Lei_de_Diretrizes_Curriculares_1996.pdf>. Acesso em: 19 fev. 2009.

ACTION AID INTERNATIONAL. Who's Really Fighting Hunger?. 2009. Disponível em: <www.actionaid.org/docs/hungerfree_scorecards.pdf>. Acesso em: 14 set. 2010.

ACTION AID INTERNATIONAL. Who's Really Fighting Hunger?. 2010. Disponível em: <http://www.actionaid.org/assets/pdf/hungerfreescorecardstwo.pdf>. Acesso em: 7 maio 2010.

ALTIERI, Miguel. Agroecologia, agricultura camponesa e soberania alimentar. Revista NERA, Presidente Prudente, ano 13, n. 16, p. 22-32, jan./jun. 2010. 
BASTOS, Élide Rugai. Pensamento social na Escola Sociológica Paulista. In: MICELI, Sérgio. $O$ que ler na Ciência Social Brasileira. São Paulo: Sumaré; Brasília, DF: CAPES, ANPOCS, 2002.

CARDOSO, Ciro Flamarion S. A brecha camponesa no sistema escravista. In: WELCH, Clifford A et al. (Orgs.). Camponeses brasileiros: leituras e interpretações clássicas. São Paulo: UNESP; Brasília: NEAD, 2009.

CARNEIRO, Edison. O quilombo dos Palmares. 2. ed. São Paulo: Cia Ed. Nacional, 1958. (Biblioteca Pedagógica Brasileira. Série Brasiliana, v. 302).

CARVALHO, Daniel de. Discursos e Conferências. Rio de Janeiro: Civilização Brasileira, 1941.

CASTRO, Josué de. As áreas alimentares do Brasil. América Indígena, México, v. 5, n. 3, p. 192-205, jul. 1945.

CASTRO, Josué de. Geografia da fome: a fome no Brasil. Rio de Janeiro: O Cruzeiro, 1946.

CHAYANOV, A. V. La organización de la unidad economica campesina. Buenos Aires: Ediciones Nueva Visión, 1974.

HEREDIA, Beatriz; PALMEIRA, Moacir; LEITE, Sérgio. Sociedade e economia do "Agronegócio" no Brasil. Revista Brasileira de Ciências Sociais, São Paulo, v. 25, n. 74, p. 159-176, out. 2010.

IAMAMOTO, Marilda. O Serviço Social na cena contemporânea. In: Serviço Social: direitos sociais e competências profissionais. Brasília: CFESS/CEAD/UnB, 2009.

IANNI, Octávio. A utopia camponesa. In: WELCH, Clifford A. et al. (Orgs.). Camponeses brasileiros: leituras e interpretações clássicas. São Paulo: UNESP; Brasília: NEAD, 2009.

MAZOYER, Marcel; ROUDART, Laurence. História das agriculturas do mundo: do neolítico à crise contemporânea. Lisboa: Instituto Piaget, 1998.

PETERSEN, P. Introdução. In: Agricultura familiar camponesa na construção do futuro. Rio de Janeiro: AS-PTA, 2009.

PETERSEN, P.; DAL SOGLIO, F.; CAPORAL, F. Construção de uma 
ciência a serviço do campesinato. In: PETERSEN, P. (Org.). Agricultura familiar camponesa na construção do futuro. Rio de Janeiro: AS-PTA, 2009.

PLOEG, J. D. van der. Sete teses sobre agricultura camponesa. In: PETERSEN, P. (Org.). Agricultura familiar camponesa na construção do futuro. Rio de Janeiro: AS-PTA, 2009.

SANTOS, Isabél Peres dos; FERRANTE, Vera Lúcia Silveira Botta (Orgs.). Da terra nua ao prato cheio: produção para consumo familiar nos assentamentos rurais do Estado de São Paulo. Araraquara: Fundação ITESP/UNIARA, 2003.

SANTOS, José Vicente Tavares dos. Conflitos agrários e violência no Brasil: agentes sociais, lutas pela terra e reforma agrária. In: SEMINARIO INTERNACIONAL, Bogotá, Colombia, ago. 2000. Bogotá: Pontificia Universidad Javeriana, 2000. Disponível em: <http://biblioteca.clacso.edu.ar/ar/libros/rjave/paneles/tavares. pdf>. Acesso em: 20 jul. 2011.

SCHAPPO, Sirlândia. Josué de Castro por uma agricultura de sustentação. 2008. Tese (Doutorado em Sociologia) - Programa de Pós-graduação em Sociologia da Universidade Estadual de Campinas, Unicamp, 2008.

WANDERLEY, Maria de Nazareth Baudel. Raízes históricas do campesinato brasileiro. In: ENCONTRO ANUAL DA ANPOCS, 20, 1996, Caxambu. Anais... Caxambu, MG, out. 1996. Grupo de Trabalho 17: Processos sociais agrários. 